\title{
Development of an Impedance Locus Model for a Protective Relay Dynamic Test with a Digital Simulator
}

\author{
Soo-Nam Kim*, Myoung-Soo Lee**, Jae-Gyu Lee***, \\ Sang-Bong Rhee ${ }^{* * * *}$ and Kyu-Ho Kim ${ }^{\dagger}$
}

\begin{abstract}
This paper presents a method for the development of the impedance locus to test the dynamic characteristics of protective relays. Specifically, using the proposed method, the impedance locus can comprise three impedance points, and the speed of impedance trajectory can be adjusted by frequency deviation. This paper is divided into two main sections. The first section deals with the configuration of impedance locus with voltage magnitude, total impedance magnitude, and impedance angle. The second section discusses the control of the locus speed with the means of the deviation between two frequencies. The proposed method is applied to two machine equivalent systems with offline simulation (i.e., PSCAD) and real-time simulation (i.e., real-time simulation environment) to demonstrate its effectiveness.
\end{abstract}

Keywords: Apparent impedance locus, Power swing blocking, Power system stability, Protective relay dynamic test, Out-of-step tripping, Real-time digital simulator

\section{Introduction}

Protective relays are playing an increasingly important role in the performance of complex and highly interconnected power systems. Proper testing and evaluation of the correct operation before the deployment of relays is therefore becoming increasingly imperative. However, the traditional method of relay testing has limited efficacy because the protective relay performance is not entirely determined by the changes in current and voltage occurring during a fault. The effect of transient phenomena should be considered. Because of these reasons, relay manufacturers and utility engineers require test methods that are more rigorous than the static test presently used. A recent advance in meeting this requirement is the application of real-time digital simulators, such as real-time simulation environment (RTDS) [1]-[4]. This new application enables many protective relay engineers to build interesting and dynamic test models [5].

This paper presents an apparent impedance locus model for dynamically testing protective relays. The model is based on the slow oscillation of the voltage angles between two sources that can affect the out-of-step relay, which in turn uses the change of apparent impedance [6] and [7]. The method of configuration for impedance locus with real-time digital simulation environment is also presented to test the blocking and tripping schemes in the distance

\footnotetext{
$\dagger \quad$ Corresponding Author: Dept. of Electrical Eng., Hankyong University, Korea. (kyuho@hknu.ac.kr)

* Hyundai Heavy Industries Co., Korea.

** Hanyang University, Korea.

*** Dept. of Electrical Eng., Daeduk College, Korea.

**** ATT Co., Korea.

Received: February 5, 2010; Accepted: January 26, 2011
}

relay [8]. The conventional dynamic test method can make only the impedance magnitude; however, the proposed test method can dictate the direction and speed of impedance trajectory.

\section{Dynamic Test of Power Swing Blocking and Out-of-step Tripping}

\subsection{Protective Relay Dynamic Test with RTDS}

The dynamic test of protective relay is normally tested by RTDS. RTDS can enable the virtual fault trajectory to be controlled by voltage magnitude and frequency deviation.

Fig. 1 shows the connection between simulation environment and protective relay for testing.

\subsection{Power Swing Detection and Blocking}

During the power swing, the block of mal-trip in the distance relay is normally carried by the power swing detector (PSD). The conventional PSD measures the time required for the apparent impedance to travel through a predefined

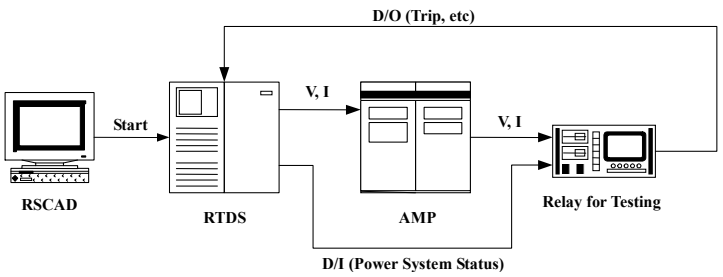

Fig. 1. Configuration for dynamic testing of protective relay. 


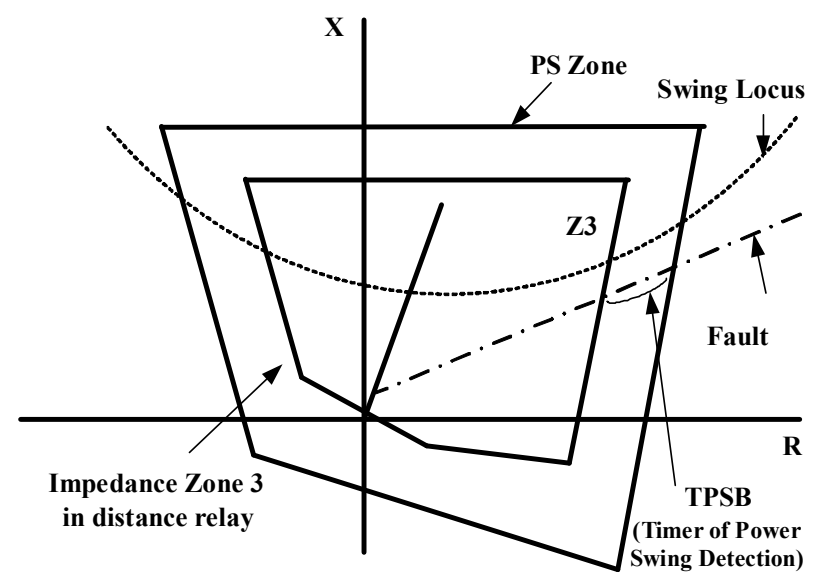

Fig. 2. General power swing detection.

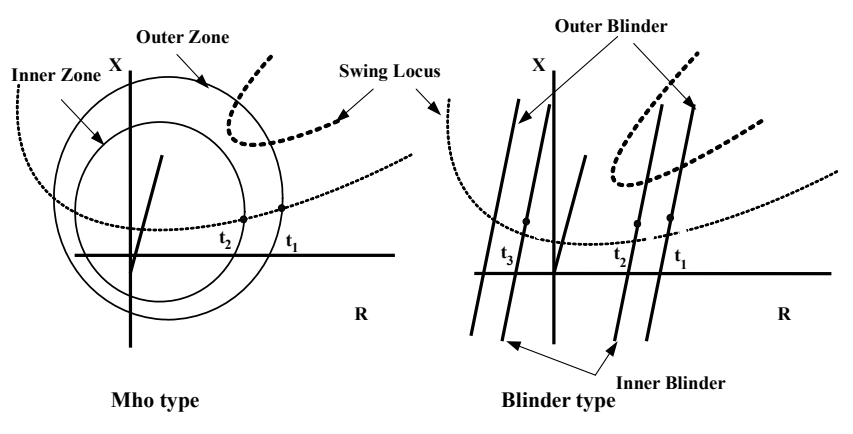

(a)

(b)

Fig. 3. General out-of-step algorithms.

impedance area in the $R$ - $X$ diagram located outside the area of the zones of operation. Fig. 2 illustrates how power swing blocking is accomplished. During the swing, the impedance locus moves slowly toward a relay characteristic through the power swing zone.

\subsection{Out-of-Step Tripping}

Fig. 3 shows typical out-of-step relay characteristics. Fig. 3 a presents the use of two concentric impedance circles in the case of mho-type zones. Fig. 3b shows a different zone, known as "blinders," implemented by a couple of straight lines in the $R-X$ diagram. The inner blinder and zone are used to detect an unstable swing. The outer blinder and zone are used to start a timer; if the impedance locus crosses the inner zone before the timer runs out, a fault is declared, and normal protection functions take over. If the impedance locus enters the inner zone after the timer runs out, the locus concludes as a power swing. In contrast, if the locus remains within the inner zone longer than a certain amount of time or passes the opposite blinder, it becomes distinguished as an unstable swing; otherwise, it becomes known as stable swing. No tripping is permitted in the case of a stable swing, whereas tripping or blocking is initiated after an unstable swing is detected.

\section{Modeling of Apparent Impedance during the Power Swing}

\subsection{Configuration of Impedance Locus}

A simple example of the power swing condition is shown in Fig. 4, where a transmission line is represented by its impedance and the power system is represented by the Thevenin equivalent impedances to the right and left of the line, respectively. The phase of the source voltage $V_{s 2}$ varies depending on the phase of the voltage $V_{s 1}$. The locus of the voltage creates a circle in the complex plane. The voltage at the midpoint of the transmission line is also described by a circle and is nearly zero in magnitude when the two source voltages are $180^{\circ}$ apart and their magnitudes are identical. The apparent impedance of the distance relay at the midpoint is moving toward the origin, especially when the line current is at maximum and the voltage is at minimum. This is viewed by the distance relay as a three-phase fault at this particular point. Therefore, the distance relay needs to distinguish power swing condition and the three-phase fault.

For a more general case,

$$
\frac{\mathbf{V}_{\mathbf{s} \mathbf{1}}}{\mathbf{V}_{\mathbf{s} \mathbf{2}}}=n e^{j \theta}
$$

where $\theta$ is the deviation between the two source angles. The voltage ratio is as follows:

$$
\frac{\left|V_{s 1}\right|}{\left|V_{s 2}\right|}=n
$$

If the total impedance includes a source impedance and the relay is located in Point A in Fig. 4, the apparent impedance locus is as shown in Fig. 5, and the center of the impedance circle is expressed as follows:

$$
\left.\begin{array}{rl}
C_{R} & =\left|Z_{T}\right| \cos \phi+\alpha \cos \phi \\
C_{X} & =\left|Z_{T}\right| \sin \phi+\alpha \sin \phi \\
\alpha & =\frac{\left|Z_{T}\right|}{n^{2}-1} \\
\gamma & =\frac{n\left|Z_{T}\right|}{n^{2}-1}
\end{array} \quad \quad \because \frac{\left|Z_{T}\right|-\beta}{\beta}=\frac{\left|Z_{T}\right|+\alpha+\gamma}{\alpha+\gamma}=n\right)
$$

where $\phi$ is the total impedance angle. To make the swing impedance locus, the ratio of the two source voltage magnitude $(n)$, total impedance magnitude $\left(\left|Z_{T}\right|\right)$, and angle $(\phi)$ are needed.

\subsection{Configuration of Power Swing Locus Model}

To test the various relay algorithms, the three points on the impedance plane should be determined. The test trajectory follows these predetermined three points during the 


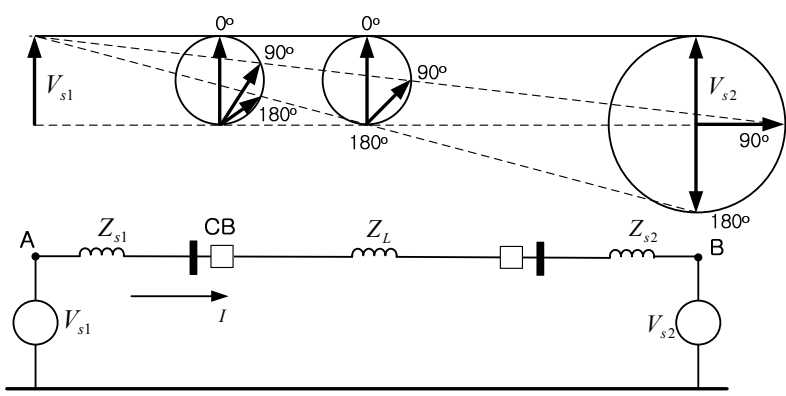

Fig. 4. Two equivalent systems during the swing.

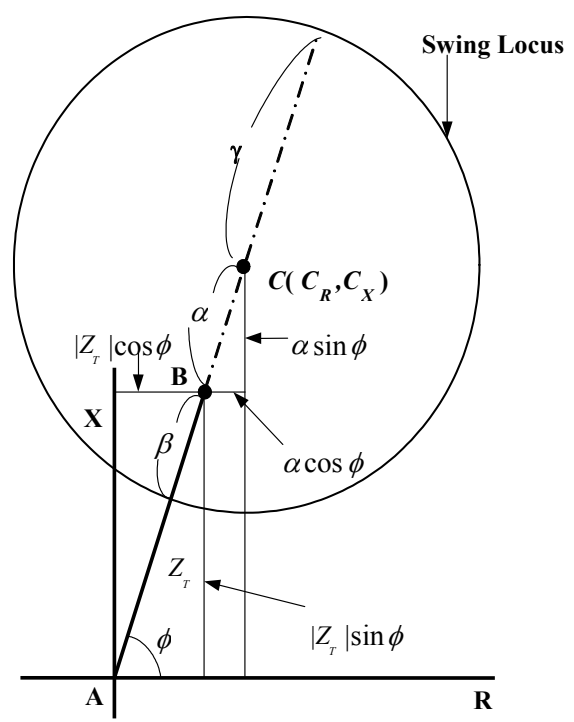

Fig. 5. Center and radius of the swing impedance locus.

test. Derivation of a circle equation becomes possible because the distinctive three points can define a circle from 4.6 in Ref. [9]. These three points are assumed as $\left(R_{1}, X_{1}\right)$, $\left(R_{2}, X_{2}\right)$, and $\left(R_{3}, X_{3}\right)$. Thus, the circle equation is

$$
\left|\begin{array}{cccc}
R^{2}+X^{2} & R & X & 1 \\
R_{1}^{2}+X_{1}^{2} & R_{1} & X_{1} & 1 \\
R_{2}^{2}+X_{2}^{2} & R_{2} & X_{2} & 1 \\
R_{3}^{2}+X_{3}^{2} & R_{3} & X_{3} & 1
\end{array}\right|=0
$$

If the equation of the circle is

$$
R^{2}+X^{2}+2 R_{0} R+2 X_{0} X+F=0
$$

the center is $\left(-R_{0},-X_{0}\right)$, and the radius is $\sqrt{R_{0}^{2}+X_{0}^{2}-F}$.

Using this equation, the $\left(C_{R}, C_{X}\right),(\gamma)$, and $F$ can be induced as follows:

$$
C_{R}=\frac{B}{2 A} \quad, \quad C_{X}=-\frac{C}{2 A} \quad, \quad F=-\frac{D}{A} \quad, \quad \gamma=\sqrt{C_{R}^{2}+C_{X}^{2}-F}
$$

where

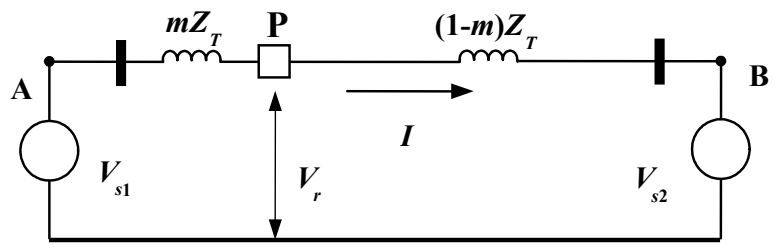

Fig. 6. Location of relay in two machines equivalent circuit.

$$
\begin{aligned}
& A=R_{1}\left(X_{2}-X_{3}\right)+R_{2}\left(X_{3}-X_{1}\right)+R_{3}\left(X_{1}-X_{2}\right) \\
& B=K_{1}\left(X_{2}-X_{3}\right)+K_{2}\left(X_{3}-X_{1}\right)+K_{3}\left(X_{1}-X_{2}\right) \\
& C=K_{1}\left(R_{2}-R_{3}\right)+K_{2}\left(R_{3}-R_{1}\right)+K_{3}\left(R_{1}-R_{2}\right) \\
& D=K_{1}\left(R_{2} X_{3}-X_{2} R_{3}\right)+K_{2}\left(R_{3} X_{1}-X_{3} R_{1}\right)+K_{3}\left(R_{1} X_{2}-X_{1} R_{2}\right) \\
& K_{1}=R_{1}^{2}+X_{1}^{2}, K_{2}=R_{2}^{2}+X_{2}^{2}, K_{3}=R_{3}^{2}+X_{3}^{2}
\end{aligned}
$$

After obtaining the center and radius by Eq. (6), the values of $n$ and $\left|Z_{T}\right|$ that satisfy Eq. (3) can be expressed as follows:

$$
\begin{aligned}
n & =\sqrt{\left(\frac{C_{R}}{\gamma}\right)^{2}+\left(\frac{C_{X}}{\gamma}\right)^{2}} \\
\phi & =\tan ^{-1}\left(\frac{C_{X}}{C_{R}}\right) \\
\left|Z_{T}\right| & =\gamma\left\{\frac{\left(\frac{C_{R}}{\gamma}\right)^{2}+\left(\frac{C_{X}}{\gamma}\right)^{2}-1}{\sqrt{\left(\frac{C_{R}}{\gamma}\right)^{2}+\left(\frac{C_{X}}{\gamma}\right)^{2}}}\right\}
\end{aligned}
$$

\subsection{Calculation of Apparent Impedance between Two Voltages}

The power swing detection and out-of-step algorithms in protective relays normally use the way of sensing the apparent impedance movement speed through the two blinders. This movement speed can be determined by proper system conditioning; thus, controlling the necessary locus speed usually requires a high level of attention. The relay located in Point $\mathrm{P}$ is assiumed to be a ratio $(\mathrm{m})$ between two lengths in two machines equivalent circuit (Fig. 6).

Because the angular frequencies of the two voltages are respectively $\omega_{1}$ and $\omega_{2}$, the voltages can be expressed as follows:

$$
\begin{aligned}
& V_{s 1}(t)=\left|V_{s 1}\right| \sin \left(\omega_{1} t+\theta_{1}\right) \\
& V_{s 2}(t)=\left|V_{s 2}\right| \sin \left(\omega_{2} t+\theta_{2}\right)
\end{aligned}
$$

If Eq. (8) is converted into phasor, then $V_{s 1}(t)$ can be converted to Eq. (9), and $V_{s 2}(t)$ can be converted to Eq. (10) 
as reference $V_{s 1}(t)$ :

$$
\begin{gathered}
\mathbf{V}_{\mathbf{s} 1}=\left|V_{s 1}\right| \angle \theta_{1} \\
V_{s 2}(t)=\left|V_{s 2}\right| \sin \left(\omega_{1} t+\left(\omega_{2}-\omega_{1}\right) t+\theta_{2}\right) \\
\mathbf{V}_{\mathbf{s} 2}=\left|V_{s 2}\right| \angle \delta(t)
\end{gathered}
$$

where

$$
\delta(t)=\Delta \omega t+\theta_{2} \text { and } \Delta \omega=\omega_{2}-\omega_{1}
$$

Here, $\Delta \omega$ is the difference in angular frequency between the two voltages. If the relay is located in Point $\mathrm{P}$, then the apparent impedance as shown by relay can be expressed as follows:

$$
\mathbf{Z}_{\mathrm{r}}=\frac{\mathbf{V}_{\mathrm{r}}}{\mathrm{I}}
$$

Eq. (12) can be expressed as magnitude and angle.

$$
\mathbf{Z}_{\mathbf{r}}=\left|Z_{r}\right| \angle \phi_{r}
$$

Here, $\left|Z_{r}\right|$ and $\phi_{r}$ changeperiodically. The current injected to relay is

$$
\mathbf{I}=\frac{\mathbf{V}_{\mathrm{s} 1}-\mathbf{V}_{\mathrm{s} 2}}{\mathbf{Z}_{\mathrm{T}}}
$$

where

$$
\begin{gathered}
\mathbf{Z}_{\mathbf{T}}=\left|Z_{T}\right| \angle \phi_{Z T} \\
\mathbf{V}_{\mathbf{s} \mathbf{1}}-\mathbf{V}_{\mathbf{s} \mathbf{2}}=\left|V_{12}\right| \angle \theta_{12}
\end{gathered}
$$

The indivual terms in Eq. (16) can be expanded as follows:

$$
\begin{gathered}
\left|V_{12}\right|=\sqrt{\left|V_{s 1}\right|^{2}+\left|V_{s 2}\right|^{2}-2\left|V_{s 1}\right|\left|V_{s 2}\right| \times k} \\
k=\cos \theta_{1} \cos \left(\Delta \omega t+\theta_{2}\right)+\sin \theta_{1} \sin \left(\Delta \omega t+\theta_{2}\right) \\
\theta_{12}=\tan ^{-1} \frac{\left|V_{s 1}\right| \sin \theta_{1}-\left|V_{s 2}\right| \sin \left(\Delta \omega t+\theta_{2}\right)}{\left|V_{s 1}\right| \cos \theta_{1}-\left|V_{s 2}\right| \cos \left(\Delta \omega t+\theta_{2}\right)}
\end{gathered}
$$

In the position $\mathrm{P}$, the voltage is

$$
\mathbf{V}_{\mathbf{r}}=(1-m) \mathbf{V}_{\mathbf{s} 1}+m \mathbf{V}_{\mathbf{s} 2}
$$

Using Eqs. (9) and (11), $V_{r}$ is

$$
\mathbf{V}_{\mathbf{r}}=(1-m)\left|V_{s 1}\right| \angle \theta_{1}+m\left|V_{s 2}\right| \angle\left(\Delta \omega t+\theta_{2}\right)
$$

The voltage magnitude and angle can be simplified to

$$
\mathbf{V}_{\mathbf{r}}=\left|V_{r}\right| \angle \theta_{r}
$$

where

$$
\begin{gathered}
\left|V_{r}\right|=\sqrt{(1-m)^{2}\left|V_{s 1}\right|^{2}+m^{2}\left|V_{s 2}\right|^{2}+2(1-m) m\left|V_{s 1}\right|\left|V_{s 2}\right| \times k} \\
\theta_{r}=\tan ^{-1} \frac{(1-m)\left|V_{s 1}\right| \sin \theta_{1}+m\left|V_{s 2}\right| \sin \left(\Delta \omega t+\theta_{2}\right)}{(1-m)\left|V_{s 1}\right| \cos \theta_{1}+m\left|V_{s 2}\right| \cos \left(\Delta \omega t+\theta_{2}\right)}
\end{gathered}
$$

With Eqs. (16) and (22), the calculated apparent impedance is

$$
\mathbf{Z}_{\mathrm{r}}=\frac{\mathbf{V}_{\mathrm{r}} \mathbf{Z}_{\mathrm{T}}}{\mathbf{V}_{\mathrm{s} 1}-\mathbf{V}_{\mathrm{s} 2}}
$$

The magnitude and angle of impedance are

$$
\left|Z_{r}\right|=\frac{\left|V_{r}\right|\left|Z_{T}\right|}{\left|V_{12}\right|} \text { and } \phi_{r}=\theta_{r}-\theta_{12}+\phi_{Z T}
$$

Apparently, the magnitude and angle of impedance change periodically.

\section{Calculation of the System Parameter for Impedance Locus}

The foregoing method was applied to the three cases as shown in Fig. 7. The test subject, an impedance relay, had rectangular characteristics. Case 1 is the typical unstable swing. Case 2 passes the PS zone and Zone 3. In Case 3, Locus 3 goes through the PS zone and goes back without passing Zone 3. All the three loci affect the out-of-step relay or phase impedance relay. This test can be applied to an out-of-step relay dynamic test if the PS zone is applied to the outer blinder of out-of-step relay and Zone 3 is applied to the inner blinder.

To make the swing of three cases in the impedance plane, the three points of each case must be determined to conFig. the corresponding impedance circle. The arbitrary three points are shown in Fig. 8.

The results of calculating the center and radius at each case using Eq. (6) are shown in Table 1.

To obtain the impedance magnitude, angle, and voltage ratio, the calculated center and radius for Eq. (7) can be substituted. The result is shown in Table 2.

Fast Fourier transform can be used to calculate the apparent impedance. The reference voltage is $V_{s 1}$ as 1.0 p.u. For the purpose of variation of voltage angle, $V_{s 1}$ can be set as $60.5 \mathrm{~Hz}$ from the reference $V_{s 2}$ with $60 \mathrm{~Hz}$. Line impedance can be converted into inductance and resistance to set up the simulation case.

Three impedance trajectories from the cases are presented in Fig. 9. Each individual plot in Figs. 9a-9c depicts the trajectories after transient state during $0.1 \mathrm{~s}$. The loci traversing through the given points are also apparent. The loci move from right to left toward origin. This movement 


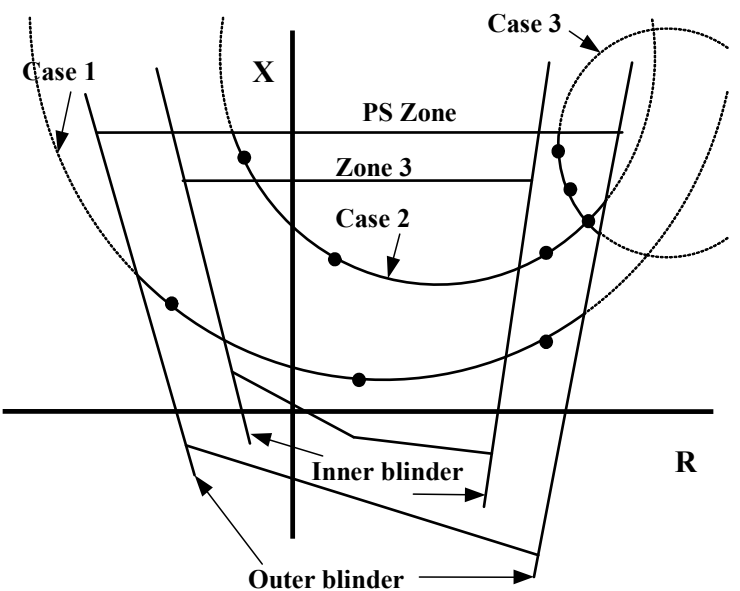

Fig. 7. Impedance swing loci for test.

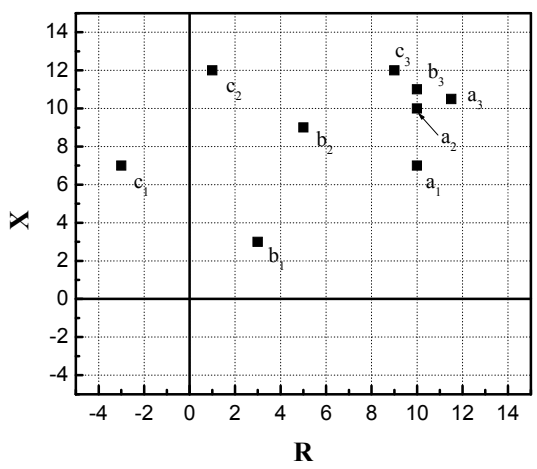

Fig. 8. Swing loci via three points $(\Omega)$ in each case.

comes from $60.5 \mathrm{~Hz}$ as $V_{s 1}$. Otherwise, the loci fall into the opposition direction.

\section{Calculation of the Frequency for the Speed of the Impedance Locus}

If the deviation of the angular frequency between two voltage sources is constant, the impedance angle changes periodically.

The accuracy of Eqs. (8)-(26) is confirmed by comparing the impedance locus calculated with offline EMTPtype simulation software (i.e., PSCAD). The testing of relays can incorporate power swing blocking or out-of-step tripping by predetermining the time required for the impedance locus to pass the specific range. The necessary predetermination can be made by changing the frequency deviation between the two voltage sources. The calculation process of apparent impedance between the two voltages was proven by a comparison with output data from PSCAD simulation. Fig. 10 shows the $R$ and $X$ variation, respectively.

The figures demonstrate that values agree with one another, except for the very early transients in PSCAD. This resemblance in periodic changes allows the output values

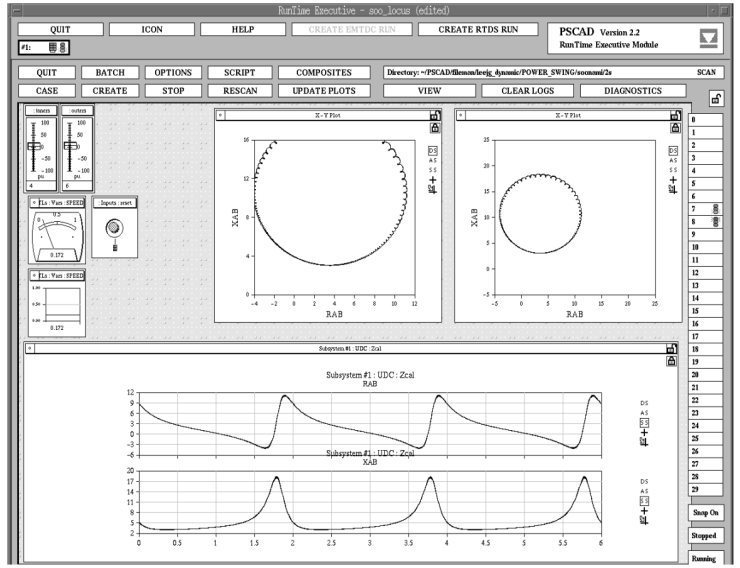

(a)

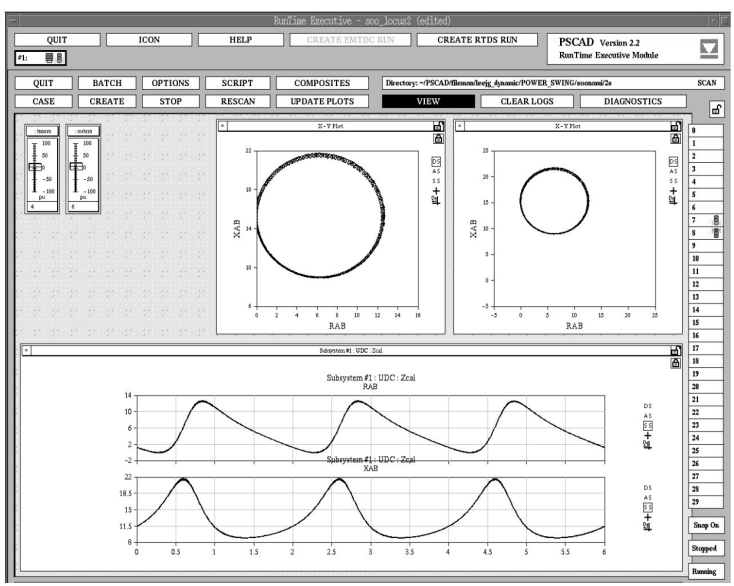

(b)

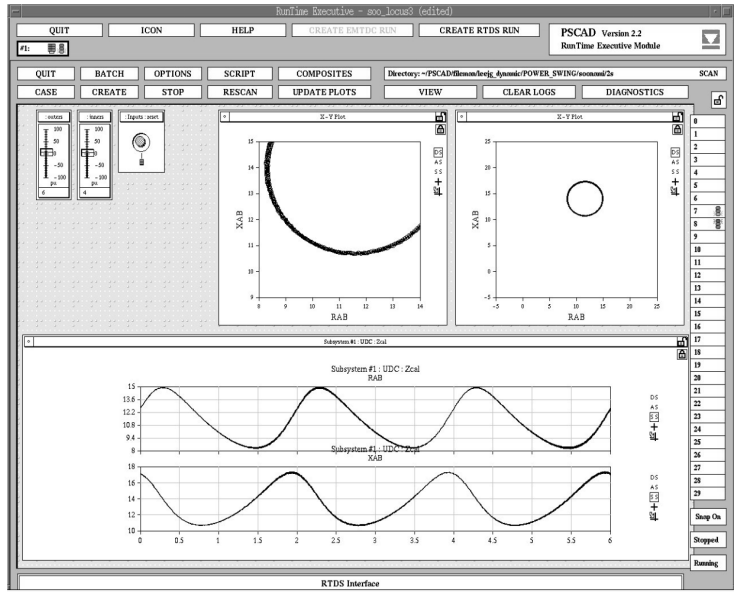

(c)

Fig. 9. Swing loci with RTDS: (a) Case 1, (b) Case 2, and (c) Case 3.

in transient state values to be ignored during testing after a steady state is reached in dynamic testing by real-time simulation.

If the relay is set by sending trip signal when the locus moves faster than $50 \mathrm{~ms}$ from 6 to $4 \Omega$ in $R$ value, and is set by sending a blocking signal when the locus moves 
Table 1. Center and radius of impedance swing loci to test

\begin{tabular}{c|c|c|c|c|c}
\hline & $\begin{array}{c}\text { Point (a) } \\
\left(R_{1}, X_{1}\right)\end{array}$ & $\begin{array}{c}\text { Point (b) } \\
\left(R_{2}, X_{2}\right)\end{array}$ & $\begin{array}{c}\text { Point (c) } \\
\left(R_{3}, X_{3}\right)\end{array}$ & $\begin{array}{c}\text { Center } \\
\left(C_{R}, C_{X}\right)\end{array}$ & Radius $(\gamma)$ \\
\hline Case 1 & $(10,7)$ & $(3,3)$ & $(-3,7)$ & $(3.5,10.25)$ & 7.26 \\
\hline Case 2 & $(10,10)$ & $(5,9)$ & $(1,12)$ & $(6.39,15)$ & 6.19 \\
\hline Case 3 & $(11.5,10.5)$ & $(10,11)$ & $(9,12)$ & $\begin{array}{c}(11.75, \\
13.75)\end{array}$ & 3.26 \\
\hline
\end{tabular}

Table 2. Impedance swing model parameter

\begin{tabular}{c|c|c|c}
\hline Parameter & Case 1 & Case 2 & Case 3 \\
\hline Voltage ratio $(n)$ & 1.49 & 2.64 & 5.55 \\
\hline $\begin{array}{c}\text { Impedance magnitude } \\
\left(Z_{T} \mid\right)\end{array}$ & 5.95 & 13.99 & 17.45 \\
\hline Impedance angle $\left({ }^{\phi}\right)$ & $71.14^{\circ}$ & $66.95^{\circ}$ & $49.48^{\circ}$ \\
\hline$R+\mathrm{j} X$ & $1.924+\mathrm{j} 5.635$ & $5.48+\mathrm{j} 12.87$ & $11.37+\mathrm{j} 13.3$ \\
\hline
\end{tabular}
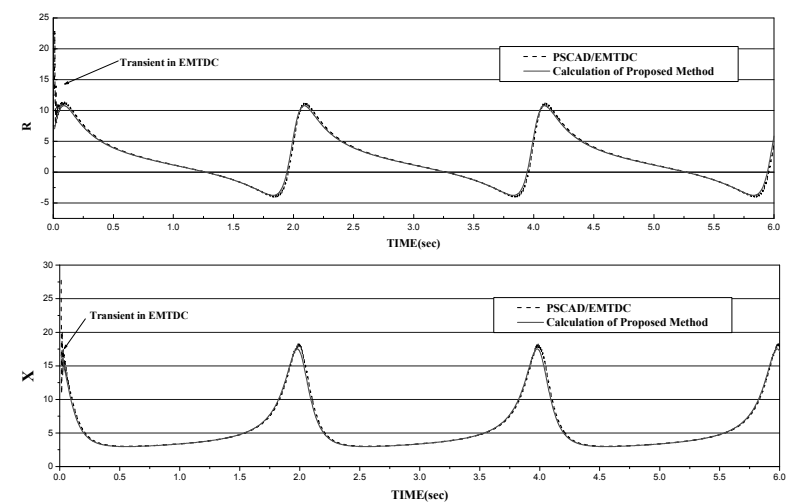

Fig. 10. Change of $R$ and $X$ components of impedance $(\Omega)$ as time.

slower than $50 \mathrm{~ms}$, then the relay testing configuration needs to make the locus speed faster or slower than $50 \mathrm{~ms}$ when the locus of $R$ passes from 6 to $4 \Omega$. In the case study, the proposed method makes the locus of $R$ pass from 10 to $-3 \Omega$, as in Case 1, as shown in Fig. 11 .

In addition, the result of the calculation suggests that the frequency difference value is $1.6 \mathrm{~Hz}$ for $50 \mathrm{~ms}$. In contrast, the correct and incorrect action can be tested by using the predetermined voltage source frequencies around $1.6 \mathrm{~Hz}$ from the proposed calculation method. Fig. 12 shows the speed calculated by different frequency values when the locus passes the two setting values. The result shows that, as the frequency difference increases, the speed of impedance change is increased as well. Thus, if the relay the time setting to be tested is $50 \mathrm{~ms}$, such as in Case 1, the frequency of $V_{2}$ voltage can be set as $61.6 \mathrm{~Hz}$ when the $V_{1}$ voltage is set to $60 \mathrm{~Hz}$ during the RTDS dynamic testing.

\section{Conclusion}

This paper presents a method to perform a dynamic test for power swing blocking and out-of-step tripping of a pro-

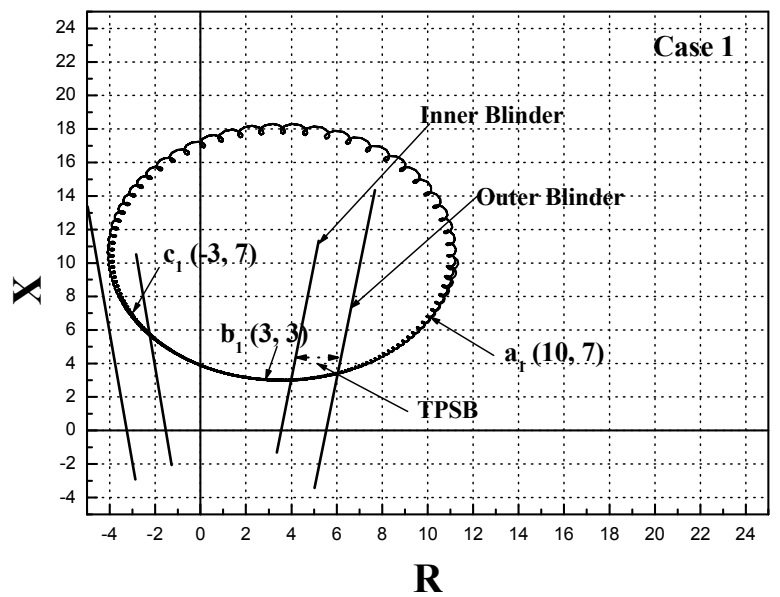

Fig. 11. Impedance locus $(\Omega)$ passing the two blinders.

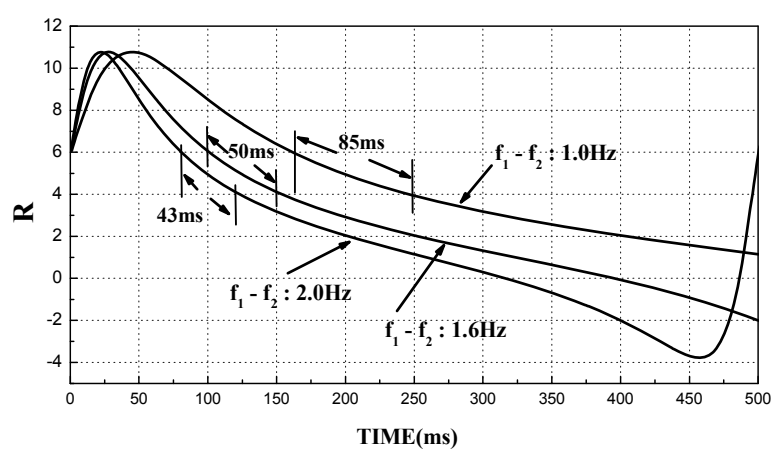

Fig. 12. Speed of impedance locus $(\Omega)$ as deviation of frequency.

tective relay. The calculation method of impedance locus using system parameters was proposed to test the protective relay algorithms of distance relays. Moreover, the speed of impedance locus change at the specific frequency deviation between the two voltage sources was calculated. With the advantage of the proposed method, the various speed and shape of impedance trajectories were created to test the protective relay algorithms (quadrilateral- or mhotype) and setting values of relays. To validate the effectiveness of the proposed method, the output data from offline simulation software (PSCAD) and RTDS were used. Analysis of the simulation results demonstrates that the proposed method enables dynamic testing of various relay elements with non-real-time and real-time simulations. The determination of the impedance trajectory direction should be investigated as a refinement of the proposed method. The proposed modeling method of impedance locus and dynamic test with RTDS can be applied to various relay based on impedance including distance relay.

\section{Acknowledgements}

This work was supported by the Human Resources Development of the Korea Institute of Energy Technology 
Evaluation and Planning (KETEP) grant funded by the Korea government Ministry of Knowledge Economy (No. 2007-P-EP-HM-E-09-0000).

\section{References}

[1] P. G. McLaren, R. Kuffel, R. Wierckx, J. Giesbrecht and L. Arendt, "A Real Time Digital Simulator For Testing Relays", IEEE Transaction On Power Delivery, Vol. 7, No.1, January 1992.

[2] Wei-Jen Lee, Ren-Jun Li and Jyh-cherng Gu, "A Microcomputer-Based Testing Station For Dynamic and Static Testing of Protective Relay System", Conference Record, Paper Presented at the 1995 Annual Meeting, 1995.

[3] R. Kuffel, P. Forsyth, H. Meiklejohn and J. Holmes, "Batch Mode Operating Software for Relay Tet Applications of the RTDS ${ }^{\mathrm{TM}}$ Simulator", Proceedings of EMPD(Energy Management and Power Delivery) 1998 International Conference on, Vol. 1, 1998.

[4] Jin-Hong Jeon, Seul-Ki Kim, Chang-Hee Cho, JongBo Ahn, Eung-Sang Kim, "Development of Simulator System for Microgrids with Renewable Energy Sources", Journal of Electrical Engineering \& Technology, 2006.12, pp. 409-413.

[5] M. Monseu, Convener, "Evaluation of characteristics and performance of power system protection relays and protective systems", CIGRE Working Group 04 of Study Committee 34(protection).

[6] Edward Wilson Kimbark, Power System Stability Volume II Power Circuit Breakers and Protective Relays, John Wiley \& Sons, 1950.

[7] Edith Clarke, Circuit Analysis of A-C Power Systems, John Wiley \& Sons, 1950.

[8] Wen-Hao Zhang, Seung-Jae Lee, Myeon-Song Choi, "Setting Considerations of Distance Relay for Transmission Line with STATCOM", Journal of Electrical Engineering \& Technology, 2010.11, pp. 522-529

[9] Daniel Zwillinger, Standard Mathematical Tables and Formulae, CRC, 1996.

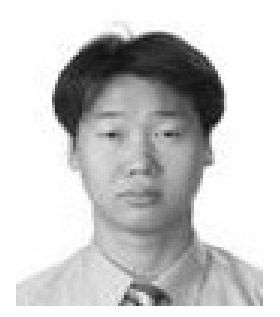

Soo-Nam Kim received his B.S., M.S., and Ph.D. degrees from Hanyang University, Korea, in 1996, 1998, and 2003, respectively. Currently, he is a Senior Researcher in Hyundai Heavy Industries Co., Kyeonggi-do, Korea. His research interests include power system stability and control, protective

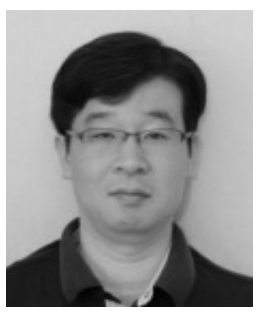

Myoung-Soo Lee received his B.S., M.S., and Ph.D. degrees from Hanyang University, Korea, in 1996, 1999, and 2003, respectively. He served as a Researcher at HanWoo Tech Co., Ltd., in Kyeonggi-do, Korea. His research interests include power system control and protection.

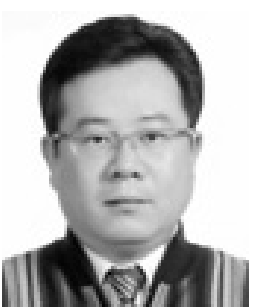

Jae-Gyu Lee received his M.S. and Ph.D. degrees from Hanyang University, Korea, in 1990 and 2003, respectively. He served as a Senior Researcher of Power System Laboratory at LS Industrial Systems Co., Ltd., in Kyeonggi-do, Korea. Currently, he is an Associate Professor at the Department of Electrical Engineering at Daeduck University in Daejeon-si, Korea. His research interests include a digital protective relay and power system.

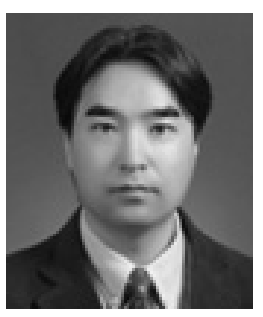

Sang-Bong Rhee received the B.S., M.S., and Ph.D. degrees from Hanyang University, Korea, in 1994, 1999, and 2004, respectively. He served as a Research Professor at the School of Electrical and Computer Engineering, Sungkyunkwan University, Korea. Currently, he is a Director of R/D at Allegiance To Technology (ATT Co.). His research interests include a distribution system control and operation, and artificial intelligence applications to power system protection.

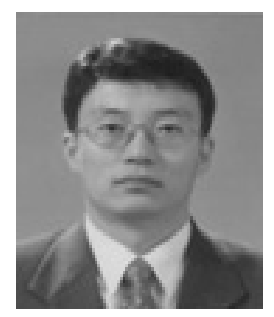

Kyu-Ho Kim received his B.S., M.S., and Ph.D. degrees from Hanyang University, Korea, in 1988, 1990, and 1996, respectively. He was an Associate Professor at the Department of Electrical Engineering at Ansan College of Technology, Kyeonggi-do, Korea. Currently, he is an Assistant Professor at the Department of Electrical Engineering at Hankyong National University, Kyeonggi-do, Korea. His research interests include power system control and operation, optimal power flow, and evolutionary computation.

systems. 